\title{
Studies on physical and rheological properties of cervico-vaginal mucus during early pregnancy in buffaloes (Bubalus bubalis)
}

\author{
Veenapani Sharma, Shiv Prasad and H. P. Gupta \\ Department of Veterinary Gynaecology and Obstetrics, \\ Veterinary College, G. B. Pant University of Agriculture and Technology, Pantnagar, Uttaranchal, India \\ VS: sharmaveenapani@gmail.com, SP: shivp2003@yahoo.co.uk. HPG: hpguptavgo@gmail.com \\ Corresponding author: Veenapani Sharma, email:sharmaveenapani@gmail.com \\ Received: 18-01-2013, Revised: 14-02-2013, Accepted: 15-02-2013, Published online: 20-05-2013
}

\section{How to cite this article:}

Sharma V, Prasad S and Gupta HP (2013) Studies on physical and rheological properties of cervico-vaginal mucus during early pregnancy in buffaloes (Bubalus bubalis), Vet World 6(8): 508-511, doi:10.5455/vetworld.2013.508-511

\begin{abstract}
Aim: The present work was carried out to study and compare the variation in physical and rheological (study of stretch and elasticity) properties of cervico-vaginal mucus of pregnant and non pregnant animals which could be used for early pregnancy diagnosis in buffaloes.

Materials and Methods: Cervico-vaginal mucus samples were obtained from 30 buffaloes ( $\mathrm{n}=12$ pregnant, $\mathrm{n}=18 \mathrm{non}$ pregnant) and a comparison was made between values of different parameters obtained from pregnant and non pregnant animals. Transparency, consistency, and elasticity of mucus were studied during early pregnancy.

Results: Transparency and consistency did not show any remarkable difference between pregnant and non pregnant animals during any phase of estrous cycle. However, rheological property i.e. elasticity, showed a significant difference in its value on $9^{\text {th }}$ day of estrous cycle. Spinnbarkeit value decreased significantly in pregnant animals on $9^{\text {th }}$ day $(3.9 \pm 0.45 \mathrm{~cm})$, whereas non pregnant group did not show a remarkable difference ( $8.4 \pm 0.43)$. Spinnbarkeit value was unidentifiable from $12^{\text {th }}$ day onward in both the groups.
\end{abstract}

Conclusion: These results conclude that significant variation in mucus elasticity could be helpful in designing user friendly tool for early pregnancy diagnosis in buffalo in future.

Keywords: cervico-vaginal mucus, color, consistency, early pregnancy diagnosis, elasticity, physical and rheological properties,

\section{Introduction}

Cervical mucus $(\mathrm{CM})$ is continuously produced by the secretory cells of the endocervix, and its quality and quantity vary depending upon the hormonal status of the estrous cycle [1]. Pregnancy detection in the bovine has been the subject of numerous investigations aimed at developing more practical and reliable diagnostic methods. Manual palpation via rectum generally has been considered as the standard and common method but it cannot be reliably applied before two months of gestation [2]. Some researchers have claimed that pregnancy determination with rectal palpation is risky even if implantation has been achieved $[3,4]$. Other methods like radioimmunoassay (RIA) for progesterone assay in milk/ plasma and early pregnancy factor (EPF) determination have limited applicability under field conditions due to high cost of equipment, lack of sophistication as well as non availability of highly trained technical staff.

Considering the lack of an ideal method of early pregnancy diagnosis, the present work was undertaken to study the variation in physical and rheological properties of cervico-vaginal mucus of pregnant and

This article is an open access article licensed under the terms of the Creative Commons Attribution License (http://creativecommons. org/licenses/by/2.0) which permits unrestricted use, distribution and reproduction in any medium, provided the work is properly cited. non pregnant animals which may help in future for development of an early pregnancy diagnosis tool in buffaloes.

\section{Materials and Methods}

Ethical approval: Adequate measures were taken to minimize the pain or discomfort in accordance with the International Animal Ethics Committee. Study was approved by the committee framed for the research by the university authority.

Study area: The present study was conducted from December 2011 to March 2012 at Govind Ballabh Pant University of Agriculture \& technology. Cervico-vaginal mucus samples were obtained from 30 buffaloes $(n=12$ pregnant, $\mathrm{n}=18$ non pregnant) (Table-1) and a comparison was made between values of different parameters obtained from pregnant and non pregnant animals. Color, consistency and elasticity of cervico-vaginal mucus were taken immediately after collection.

Selection of animal: Samples of cervico-vaginal mucus were taken from the cervix of normal buffaloes of 3-6 years age and 2-3 parity, which were free from any genital tract infection.

Induction of heat: $2.5 \mathrm{ml}$ of a $\mathrm{GnRH}$ analogue (Receptal, $0.004 \mathrm{mg} / \mathrm{ml}$ Buserelin, Intervet India private Limited) was administered to 100 buffaloes 
Table-1. Details of samples studied.

\begin{tabular}{lllll}
\hline Area & Species & No. of Animal & Samples/Animal & Total Samples \\
\hline IDF, Pantnagar & Buffalo & 30 & day $0,3,6,9,12,15,18,21=8$ & $8 \times 30=240$ \\
\hline
\end{tabular}

Table-2. Colour of cervico-vaginal mucus in pregnant and non pregnant animals. Day $0=$ day of estrus, Day $3-21=$ days of estrous cycle

\begin{tabular}{lll}
\hline $\begin{array}{l}\text { Days of } \\
\text { estrous cycle }\end{array}$ & Non Pregnant $(\mathbf{n = 1 8 )}$ & Pregnant $(\mathbf{n = 1 2})$ \\
\hline 0 & Transparent & Transparent \\
3 & Semi transparent & Semi transparent \\
6 & Turbid & Turbid \\
9 & Turbid & Turbid \\
12 & Dirty & Dirty \\
15 & Dirty & Dirty \\
18 & Dirty & Dirty \\
21 & Turbid & Dirty \\
\hline
\end{tabular}

irrespective of the stage of their estrous cycle (day of GnRH treatment, day 0), followed by $2 \mathrm{ml}$ of PGF $2 \alpha$ (Cyclix, $263 \mu \mathrm{g} / \mathrm{ml}$ Cloprostenol Sodium, Intervet India private Limited) day 7 , and a second-GnRH treatment $(2.5 \mathrm{ml}) 48 \mathrm{~h}$ after PGF2 $\alpha$ (day 9). Out of 100 , those 30 animals which exhibited heat within 2448 hours of treatment were selected for the experiment.

Heat detection: Estrus was detected twice daily, in morning and evening. The buffaloes were also monitored both for behavioural symptoms (frequent micturition, bellowing, raised tail, restlessness and licking of external genitalia by other animals) and physical changes (vulvular edema and mucus discharge) of the reproductive tract. On the fifth day after estrus, the corpus luteum (CL) was detected by per rectal palpation to confirm the estrus phase.

Breeding of animal: Buffaloes showing signs of true estrus were bred 12 hours after the onset of estrus by natural breeding with high quality bull.

\section{Collection of cervico-vaginal mucus}

Collection procedure: Vulva was washed with a warm dilute solution of savlon. Sterilized vaginal speculum was inserted into vagina and fixed. Sterilized long handle forceps holding cervical sponge was gently inserted through vaginal speculum via vagina upto the cervix. Extreme care being used and line of least resistance always taken. Sponge was left there for few minutes and then taken out. Absorbed cervical mucus was collected in Eppendorf tubes.

Samples were taken from 30 bred animals at a gap of every 2 day, starting from day of breeding to the completion of one estrous cycle i.e.21 days, considering day 0 (day of breeding),3,6,9,12,15,18,21. Pregnancy was diagnosed after 60 days by per rectal palpation.

Storage of sample: The samples were collected in Eppendorf tubes and immediately transferred to laboratory on ice where they were marked with date, sample no and time of collection. Transparency, consistency, elasticity and $\mathrm{pH}$ of sample were taken
Table-3. Consistency of cervico-vaginal mucus in pregnant and non pregnant Thin- mucous flows easily from a slide at 45 degree angle. Thick- mucous remain sticky on a slide at 45 degree angle. Day $0=$ day of estrus, Day 3-21= days of estrous cycle

\begin{tabular}{lcc}
\hline $\begin{array}{l}\text { Days of } \\
\text { estrous cycle }\end{array}$ & Non Pregnant $(\mathbf{n = 1 8})$ & Pregnant $(\mathbf{n = 1 2 )}$ \\
\hline 0 & Thin & Thin \\
3 & Thin & Thin \\
6 & Thick & Thick \\
9 & Thick & Thick \\
12 & Thick & Thick \\
15 & Thick & Thick \\
18 & Thick & Thick \\
21 & Thick & Thick \\
\hline
\end{tabular}

immediately. Then they were stored at $-20 \mathrm{OC}$ till further processing without added preservative. Pregnancy was confirmed after 60 days on the basis of per rectal palpation. Pregnancy and non pregnancy samples were separated and different samples taken on different days were pooled separately.

Mucus was studied for transparency and consistency by visual examination. These properties were identified and classified as per Sukhdeo and Roy [5].

The transparency of cervico-vaginal mucus were classified into three main types as follows.

1. Transparent: like white of an egg

2. Turbid: cloudy in appearance

3. Dirty: not homogeneous in look, dirty, colors like yellow, ash, grey, red etc. were sometimes mixed.

The consistency of cervico-vaginal mucus was classified into two main types as follows.

1. Thin: which could flow easily on a glass slide kept inclined at $45 \mathrm{O}$ angle.

2. Thick: when mucus samples remained sticky on a glass slide and did not flow at 45 Oangle.

The elasticity of cervical mucus was observed by dropping some mucus from catheter to glass slide and then it was classified as follows.

1. Less Elastic: Less viscous, sometimes watery and formed no rope when dropped from the catheter to the glass slide.

2. Elastic: Having the property to form rope or string when dropped from the catheter to the glass slide.

3. Very Elastic: The secretion was too viscous and was difficult to drop from the catheter on glass slide and remained sticky.

Length of the rope formed was measured in centimeters.

\section{Results and Discussion}

Generally coloured cervical mucus have been reported to be a conducive factor for sperm penetration and conception whereas, turbidity in estrual mucus arrests sperm motility[6]. The estrual mucus was always transparent whereas the mucus, one day after 
Table-4. Elasticity of cervico-vaginal mucus in pregnant and non pregnant animal. Unit- length of rope (in centimeter) formed on dropping some mucus from catheter to glass slide

\begin{tabular}{lcc}
\hline $\begin{array}{l}\text { Days of } \\
\text { estrous cycle }\end{array}$ & Non Pregnant $(\mathbf{n = 1 8})$ & Pregnant $(\mathbf{n = 1 2 )}$ \\
\hline 0 & $11.0 \pm 0.12$ & $11.1 \pm 0.33$ \\
3 & $10.3 \pm 0.41$ & $10.1 \pm 0.45$ \\
6 & $9.4 \pm 0.11$ & $9.5 \pm 0.55^{*}$ \\
9 & $8.4 \pm 0.43$ & $3.9 \pm 0.45$ \\
12 & unidentifiable & Unidentifiable \\
15 & unidentifiable & Unidentifiable \\
18 & unidentifiable & Unidentifiable \\
21 & unidentifiable & Unidentifiable \\
\hline
\end{tabular}

*Significant at $0.05 \%$ level

estrus was almost transparent i.e. semitransparent or only slightly whitish in color in both pregnant and non pregnant animals. Samples $(\mathrm{n}=121)$ in non pregnant group and samples $(n=90)$ in pregnant group, starting from 3 days after estrus were yellow or white. As shown in Table-2, mucus was turbid from day 6 to day 9 and then changed to dirty from $12^{\text {th }}$ day onward in both pregnant and non pregnant group. The cervico-vaginal mucus of non pregnant animal became turbid again on $21^{\text {st }}$ day whereas in case of pregnant animal, it was found dirty from 18-21 days and was very less in amount containing cellular debris. There is probability that cellular debris is the result of breakdown from the epithelium of the reproductive tract [7]. The results are in general agreement with the findings of Woodman and Hammond [8], Sharma et al., [9] who also found the similar color patterns of cervico-vaginal mucus. As far as consistency of cervico-vaginal mucus is considered, the results were very obvious. Majority of fertile estrus had thin consistency. Similar findings of cervico-vaginal mucus consistency have been reported by Rangnekar et al. [10], Rajesh et al. [11] In both pregnant and non pregnant animal, mucus was very thin during estrus but after $3^{\text {rd }}$ day onward the consistency became thick (Table-3). The mucus was plentiful, fairly fluid and adhesive, containing no cellular debris in both pregnant and non pregnant animal at estrus. During the luteal phase the mucus became minimal, thickened, cohesive and contained little cellular debris. These observations are in agreement with those of Woodman and Hammond [8], Sharma and Tripathi [7], Sharma et al., [9].

A defined trend in transparency and consistency change in pregnant and non pregnant cervico-vaginal mucus was not found in the present study.

Mucus during estrus showed a particular type of elasticity which decreased as the estrous cycle progressed. From $12^{\text {th }}$ day onward elasticity became undetectable in both pregnant and non pregnant group. However, a significant decrease in spinnbarkeit value was observed on $9^{\text {th }}$ day in pregnant animal $(3.9 \pm 0.45$ $\mathrm{cm})$. Whereas, in non pregnant group, the reduction was less and reached to $8.4 \pm 0.43 \mathrm{~cm}$. The difference in spinnbarkeit values between pregnant and non pregnant group was found significant on $9^{\text {th }}$ day of estrous cycle. The mean spinnbarkeit value of cervical mucus in pregnant animal ranged from $3.9 \pm 0.45 \mathrm{~cm}$ to $11.1 \pm 0.33 \mathrm{~cm}$ whereas the values in non pregnant animals ranged from $11.0 \pm 0.12$ to $8.4 \pm 0.43 \mathrm{~cm}$ (Table3 ). This result is in conformity with that of Mehmood et al.,[12] who also found significant difference in spinnbarkeit value between pregnant and non pregnant animals from $9^{\text {th }}$ day onward whereas Rutllant et $a l .[13]$, did not find any significant difference in the spinnbarkeit value of cervico-vaginal mucus of pregnant and non pregnant animal.

These results are also in accordance with the results of Scott Blair et al., [14] who found that in general mucus of pregnant animal was stiff and plastic rather than elastic whereas mucus of non pregnant animal was more elastic.

The increased elasticity of mucus also increases the permeability of cervical mucus to spermatozoa. The results are in agreement with those obtained by Marcus and Marcus [15], who have reported that the Spinnbarkeit gradually increases during proliferative phase of cycle reaching a maximum at the time of ovulation. Spinnbarkeit is attributable to the presence of long chain of molecules in the mucus and is probably also dependent upon branching of molecular chains and other strong intermolecular forces Modi et al.,[16]. Woodman and Hammond [8] reported that the functional state of ovaries and their hormones had a direct relationship with the consistency and elasticity of cervical mucus.

When the animal conceived, its elasticity decreases sharply and it becomes thick and plastic, rather than elastic whereas in case of non pregnant animals the spinnbarkeit value decrease gradually[17].

Transparency and consistency did not show any remarkable difference in their pattern between pregnant and non pregnant animals during any phase of estrous cycle. However, rheological properties (elasticity) showed a marked difference. Elasticity of cervico-vaginal mucus showed a significant difference in its valueon $9^{\text {th }}$ day of estrous cycle where spinnbarkeit value decreased in pregnant animals $(3.9 \pm 0.45 \mathrm{~cm})$ than in non pregnant $(8.4 \pm 0.43)$ (Table-4). But on other days, differences were non significant. Hence it was concluded that though color and consistency were not helpful but a further and more detailed study of mucus elasticity may pave a way for development of early pregnancy diagnosis tool in buffaloes. 


\section{Conclusion}

As per our results, transparency and consistency did not show any remarkable difference between pregnant and non pregnant animals during any phase of estrous cycle as far as physical properties are concerned. However, rheological property showed a marked difference. A significant decrease in spinnbarkeit value was observed on $9^{\text {th }}$ day in pregnant animal $(3.9 \pm 0.45$ $\mathrm{cm})$, whereas in non pregnant group, the reduction was less and reached to $8.4 \pm 0.43 \mathrm{~cm}$. The difference in spinnbarkeit values between pregnant and non pregnant group was found significant on $9^{\text {th }}$ day of estrous cycle. From $12^{\text {th }}$ day onward elasticity became undetectable in both pregnant and non pregnant group.

The present study concludes that studies of elasticity (spinnbarkeit value) of cervico-vaginal mucus in pregnant animals may pave the way to find a molecule in future which could be used to evolve a cheap and handy early pregnancy diagnostic kit for large animals.

\section{Authors' contribution}

SP participated in preparation of the experimental design. HP collected the samples. VPS analysed the data, sample and wrote the final draft of different levels of the manuscript. All the authors read and approved the final manuscript.

\section{Acknowledgements}

The authors are thankful to the Dean, College of veterinary and animal science, Pantnagar and Director Research for providing the facillities for carrying out the research work. Financial help in the form of ICAR research project under NFBSRA, Govt. of India is duly acknowledged.

\section{Competing interests}

Authors declare that they have no competing interest.

\section{References}

1. Tsiligianni, Th., Karagiannidis, A., Brikas, P. and Saratsis, $\mathrm{Ph}$ (2001) Physical properties of bovine cervical mucus during normal and induced by progesterone and/or PGF2alpha estrus. Theriogenology, 55:629-640.

2. Altun, O., and Kutlay, G. K. (2011) A Comparison of Diagnosis of Early Pregnancy in Dairy Cows Via Transrectal and Transvaginal Ultrasound Scaning. J Fac Vet Med Univ
Erciyes 8(1) 17-21.

3. Thompson, J. A., Marsh, W. E., Calvin, J. A., Etherington, W. G., Momont, H. W. and Kinse, M. L. (1994) Pregnancy attrition associated with pregnancy testing by rectal palpation. J Dairy Sci, 77: 3382-3387.

4. Thurmond, M. C. and Picanso, J. P. (1993) Fetal loss associated with palpation per rectum to diagnose pregnancy in cows. J Am Vet Med Assoc, 203: 432-435.

5. Sukhdeo and Roy, D. J. (1971) Investigations on repeat breeding cows and buffaloes-studies on physical properties of cervical mucus, Indian Vet. J, 48: 479-484.

6. López-Gatius, F., Miró, J., Sebastián, I., Ibarz, A. and Labernia, J. (1993) Rheological properties of the anterior vaginal fluid from the super ovulated dairy heifers at estrus. Theriogenology, 40: 167-180.

7. Sharma, V. K. and Tripathi, S. S. (2008) Physiochenical properties of cervical mucus in relation to conception in normal and repeat breeding cross bred cows. Indian J. Anim. Reprod. 8: 39-42.

8. Woodman, H. E. and Hammond, J. (1925) The mucus secretion of cervix of cow. J. Agric. Sci., 15:107.

9. Sharma, S., Sharma, H., Dhami, A. J. and Bhong, C. D. (2008) Physico-Microbial properties of cervico-vaginal mucus and its antibiotic sensitivity pattern in repeat breeding buffaloes. J. Dairy Sci., 66:1728-1733.

10. Rangnekar, M. M., Dhoble, R. L., Gacche, M. G., Ingawale, M. V., Sawale, A. G. and Jadav, J. M. (2002) Physical properties of estrual cervical mucus in repeat breeding cross bred (Holstein - Friesian) cows with reference to fertility. Ind. J. Anim. Sci., 72(12): 1122-1124.

11. Rajesh, K., Dharmendra, K. and Roy, B. (2011) Studies on repeat breeding of buffaloes. Buffalo Bulletin Vol.30 No.3.

12. Mehmood, A., Akhtar, S., Ullah, N. and Khan, M. I. (1991) The use of probit model to predict pregnancy status of buffalo based on physiochemical properties of estrual mucus. Theriogenology, 36: 117-122.

13. Rutllant, J., López-Béjar, M., Yániz, J. and López-Gatius, F. (2005) Ultrastructural and Rheological Properties of Bovine Vaginal Fluid and its Relation to Sperm Motility and Fertilization. Reprod. in Domes. Ani. 40(2): 79-86.

14. Scott Blair, G. W., Folley, S. J., Coppen, F. M. V. and Malpress, F. H. (1942) Rheological properties of bovine cervical secretions during the oestrus cycle. Nature, 147: 453-454.

15. Marcus, C. C. and Marcus, S. L. (1968) The cervical factor. In: Progeress in infertility. Behrman S.J. and Kistner R.W. $4^{\text {th }}$ ed.Little, Brown and Company, Boston, pp: 21.

16. Modi, L. C., Suthar, B. N., Nakhashi, H. C., Sharma, V. K. and Panchasara, H. H. (2011) Physical Characteristics of Estrual Cervical Mucus and conception rate in Repeat Breeder Kankrej Cattle. IJAVMS. 2011; 5(4): 416-423.

17. Tsiligianni, Th., Georgios, S., Eleni, D., Ioannis, M., Stella, C., Dimitrios, R. and Alfonso, G. (2011) Association between physical properties of cervical mucus and ovulation rate in superovulated cows. Can J Vet Res., 75(4): 248-253 